\title{
SITUAÇÃO DE REFÚGIO E ENSINO SUPERIOR NAS IFES: UM PASSO EM DIREÇÃO À INTEGRAÇÃO?
}

\section{Refugee situation and higher education at Brazilian Federal Institutions: a step towards integration?}

http:/ / doi.org/10.17648/ revistaterritorialidades-v1n2-2
Universidade Tecnológica Federal do Paraná E-mail: lisacris@gmail.com Orcid: orcid.org/0000-0003-0348-6125

Elisa Perelles

Universidade Tecnológica Federal do Paraná E-mail: elisaperelles@gmail.com Orcid: orcid.org/0000-0002-5022-7938

Maria Lucia Figueiredo Gomes de Meza Universidade Tecnológica Federal do Paraná E-mail: malumeza2@gmail.com Orcid: orcid.org/0000-0002-1875-5140

ABSTRACT debates de dimensão econômica, política, social e, também, educacional. O presente artigo amplia o conceito de educação e discute ações afirmativas destinadas à população refugiada no contexto das Instituições de Ensino Superior Federal. Com uma metodologia construída pela revisão bibliográfica e documental, esta pesquisa qualitativa de natureza exploratória e aplicada traz como estudo de caso o programa Política Migratória e Universidade Brasileira (PMUB) da Universidade Federal do Paraná (UFPR), cujas práticas de integração serão analisadas segundo o marco de referência de Gidley et al., representado pelos 3 E's: equidade de acesso, engajamento participativo e empoderamento. Para tal, inicialmente são discutidos os dispositivos legais de proteção aos refugiados no Brasil e no mundo para, em seguida, vincular o acesso ao ensino superior como um mecanismo de exercício de cidadania e de integração na sociedade de acolhimento. Como resultado, conclui-se que, entre 2014 e 2019, grande parte das ações desenvolvidas pelo programa visa promover a equidade de acesso e engajamento participativo demonstrando, no entanto, uma lacuna potencial no que concerne à dimensão de empoderamento.

Palavras-chave: Refugiados. Ensino Superior. Integração. Ações afirmativas.
Recently, the growing number of refugees received in Brazil has brought to light numerous debates from an economic, political, and social dimension, as well as education. This article expands the concept of education and discusses positive actions oriented to the refugee population in the context of Brazilian Federal Institutions of Higher Education. With a methodology built by literature review and documentary research. This qualitative research has an exploratory and applied nature by bringing as a case study the Migration Policy and Brazilian University Program (PMUB), whose practices will be analyzed according to the framework of 3 is (equity of access, participatory engagement, and empowerment) created by J. Gidley. Initially, the legal and international mechanisms in Brazil and in the world to protect refugees are discussed. Later, the access to higher education as a strategy for exercising citizenship and integration into the host society is presented. As a result, the study has concluded that between 2014 and 2019 most of the actions developed by the program aimed to promote equity of access and participatory engagement, which demonstrates a potential gap regarding the dimension of empowerment.

Keywords: Refugees. Higher education. Integration. Positive actions. 


\section{INTRODUÇÃO}

A situação de refúgio e exílio está intimamente vinculada à violência em suas mais diversas esferas, caracterizada pela imposição, ao indivíduo, de um fim abrupto do que este conhecia como vida cotidiana para o início de uma saga em busca por acolhimento em outra nação, com a qual não necessariamente compartilha semelhanças culturais ou sociais. Além das guerras civis, as perseguições contra grupos étnicos, políticos e minorias sociais, bem como a própria crise humanitária que submete povos inteiros a condições extremas de sobrevivência e, ainda, a pobreza e o subdesenvolvimento decorrentes de governos corruptos também podem desencadear o imperativo de refúgio (KUGIEL, 2016).

O movimento migratório global, formado por pessoas que tentam sair de seus contextos político-sociais caóticos, vem ganhando relevância e exposição midiática recentemente, não apenas pelos grandes contingentes de pessoas deslocadas, mas, igualmente, por trazer à tona as mazelas dos países de origem dessas populações e ressaltar a incapacidade dos demais países em oportunizar, no mínimo, o acolhimento a esses grupos.

Na década de 2000, a Europa teve de responder ao desafio migratório mais grave desde a Segunda Guerra Mundial (UNHCR, 2017). Em 2014, o Brasil também foi surpreendido pelo agravamento da crise política e econômica, na vizinha Venezuela, e se torna o destino de uma onda migratória de solicitantes de refúgio sem precedentes na história do país.

Nas primeiras décadas do século XXI, o Brasil começou a receber um fluxo migratório de haitianos, ganeses, senegaleses e europeus. Fugindo da crise econômica da Europa, estes últimos foram atraídos pela reputação e visibilidade internacionais do Brasil no exterior, como pelo contexto de estabilidade econômica, cujo ápice foi 2014 (ASSIS, 2017).

Entretanto, esse fluxo em nada se comparou ao testemunhado nos últimos cinco anos, com a questão venezuelana. Segundo estatísticas da Polícia Federal, em 2014, o Brasil abrigava 5.208 refugiados de 79 nacionalidades - nesse mesmo ano, o número de solicitações de asilo chegou a 25.000. Em termos de comparativos, até julho de 2018, o número de solicitações de asilo já havia ultrapassado o número de 40.000 (ACNUR, 2016).

A entrada massiva desses novos indivíduos impõe desafios à realidade social local no país que os recebe. No caso do refúgio, garantir abrigo e segurança são preocupações prioritárias, de caráter emergencial e humanitário, já que esse deslocamento não acontece de maneira planejada. Em seguida, oportunizar vaga no mercado de trabalho se apresenta como uma etapa posterior natural ao processo de restabelecimento de uma rotina de vida, acompanhado pela dimensão educacional, que se coloca como um próximo passo imediato e necessário no sentido de promover a integração bem-sucedida (AGER;STRANG, 2008).

Nesse processo de integração, é comum aos recém-chegados enfrentarem desafios atrelados a conflitos identitários e culturais, ocasionados majoritariamente pelo contraste cultural que há entre a figura do recém-chegado e a sociedade de acolhimento (SMAILI, 2015). Por isso, retornar ou iniciar os estudos na sociedade de acolhimento proporciona uma sensação de estabilidade que pode servir como um poderoso contrapeso ao trauma da migração forçada (DRYDEN-PETERSON, 2016).

A integração local passa, indubitavelmente, pelo respeito às múltiplas identidades e direitos dessa população. Para que essa integração se efetive, é necessário que sejam criadas oportunidades de aprendizagem do idioma de acolhimento (se necessário), bem como de inserção laboral e educacional, na qual se inclui também o ensino superior (LAPA et al., 2019).

As estatísticas apontam que, entre os refugiados, apenas 1\% irá alguma vez transitar para o ensino superior, ou voltar a fazê-lo, em comparação com a média global de 36\% (STREITWIESER et al., 2018). Em termos acadêmicos, no Brasil, os trabalhos relacionados à temática ainda são escassos devido à atualidade do tema (DE CARVALHO, 2019; BUSKO, 2017; SILVA et al., 2018). 
Portanto, este trabalho busca contribuir para o debate sobre a função do ensino superior como um fator importante no contexto de integração da população refugiada no Brasil, notadamente a função das Instituições Federais de Ensino Superior (IFES). Diferente de grande parte das Universidades do mundo, as instituições públicas brasileiras não cobram de seus alunos as chamadas "tuition fees" ou mensalidades ${ }^{1} \mathrm{e}$ têm por missão constitucional o ensino, a pesquisa e a extensão, esta última com forte apelo social. Em decorrência da especificidade da análise desta pesquisa, foram desconsideradas iniciativas vinculadas à revalidação de diplomas, bem como programas de educação e formação profissional e intervenções promovidas por indivíduos, ONGs ou fundações.

O estudo consiste em uma pesquisa qualitativa de natureza aplicada e exploratória, buscando manter um olhar dialético que privilegie a interpretação dinâmica e total da realidade. Para construir o arcabouço teórico desse trabalho, foram revisados artigos acadêmicos e periódicos, outras publicações e sites (institucionais ou organizacionais). De igual forma, o marco analítico no qual se baseia a análise das intervenções, realizadas na cátedra do Programa Política Migratória e a Universidade Brasileira (PMUB), tem como base as pesquisas desenvolvidas por Streitwieser e Unangst (2018) e de Gidley et al. (2010), adaptadas ao contexto da UFPR, seguindo o arcabouço legal e as experiências resultantes das interações profissionais entre as pesquisadoras e o objeto de estudo.

A seleção da Universidade, alvo do estudo de caso, se justifica pelo pioneirismo do programa e seu tempo de existência, já que as atividades analisadas se desenvolvem desde 2014. O levantamento de dados primários se deu pela consulta a documentos, editais, resoluções, notícias, listagens, postagens de redes sociais (Facebook e Instagram), entre outros.

Embora este trabalho não tenha a ambição de fornecer uma visão abrangente das atividades destinadas à população refugiada em desenvolvimento no país, seu mérito se caracteriza pela proposta de avaliar o tipo de atividade desenvolvida em termos de integração, reforçando as possíveis potencialidades e os desafios na implementação de futuras políticas afirmativas com foco nessa temática.

Em termos estruturais, este artigo divide-se em seis tópicos. Além desta introdução, o segundo tópico trata do arcabouço legal e conceitual que circunda a proteção e os direitos da população refugiada. No terceiro, a ideia da educação se inter-relaciona dentro de um contexto de direitos humanos em vulnerabilidade, como é caso dos solicitantes de refúgio. Em seguida, no tópico quatro, são apresentados os 3 E's de Gidley et al. e, no tópico cinco, são analisadas as ações desenvolvidas no âmbito do Programa Política Migratória e Universidade Brasileira (PMUB), da Universidade Federal do Paraná (UFPR), que tem como principal objetivo o acolhimento de migrantes e refugiados em Curitiba e região. As ações são categorizadas segundo o marco analítico de Gidley et al., que vincula as ações afirmativas destinadas à população refugiada ao processo de integração. Finalmente, no tópico seis, as considerações finais trazem uma visão geral das potencialidades e dos desafios futuros, no contexto de refúgio.

\section{DISPOSITIVOS DE PROTEÇÃO AOS REFUGIADOS NO BRASIL E NO MUNDO}

O fluxo migratório de refugiados possui antecedentes históricos remotos, entretanto o debate internacional a respeito do tratamento adequado a ser dado à questão remonta ao estabelecimento da Sociedade das Nações, em 1919. Após a Revolução Comunista na Rússia, em 1917, e as crises no antigo Império Otomano, em 1921, o Conselho da Sociedade das Nações autorizou a criação de um Alto Comissariado para Refugiados, com a missão de tratar as questões vinculadas aos refugiados russos e armênios (RAMOS, 2011).

Anos mais tarde, em resposta às violações de direitos ocorridas durante a Segunda Guerra Mundial, foi dado um grande passo para a construção de um arcabouço legal de proteção dos direitos humanos: a Declaração Universal dos Direitos Humanos de 1948, cujo

\footnotetext{
${ }^{1}$ Tradução livre adaptada pelo(s) autor(es).
} 
artigo 14 prevê o direito ao asilo, em outros países, a toda pessoa vítima de perseguição. Com a dignidade humana como premissa de valor, esse primeiro instrumento jurídico de proteção aos direitos humanos deu origem a outros tratados de ampliação do sistema global de proteção (JUBILUT; MADUREIRA, 2014).

Em 1951, foi assinada a Convenção relativa ao Estatuto dos Refugiados, também chamada de Convenção de Genebra. Considerada a Carta Magna, quando o tema é proteção dos refugiados, ela estabelece, em caráter universal, o conceito de refugiado, seus direitos e deveres básicos e, igualmente, as possíveis razões de interrupção da condição de refugiado. No mesmo documento, estabelece-se a criação do ACNUR, o Alto Comissariado das Nações Unidas para os Refugiados, agência das Nações Unidas especializada na assistência e proteção aos refugiados.

De tal modo, refugiado passa a ser entendido como o indivíduo que se encontra fora do seu país de nacionalidade, em consequência dos acontecimentos ocorridos antes de $1^{\circ}$ de janeiro de 1951 - menção direta à Segunda Guerra Mundial - e que, por receio de ser perseguido em razão da sua raça, religião, nacionalidade, filiação em certo grupo social ou das suas opiniões políticas, não quer ou não pode retornar (CALAZANS; PACÍFICO; MENDONÇA, 2010).

Com o passar dos anos, a limitação temporal e os novos desafios impostos tornaram obsoleto tal conceito. Os novos grupos de refugiados que surgiram já não se encaixavam no escopo da Convenção de Genebra, por essa razão, o Protocolo de 1967 é adotado, expandindo as limitações geográficas e temporais presentes no documento anterior e ampliando o conceito de refugiado com o intuito de promover a proteção de um maior número de populações em vulnerabilidade (CALAZANS; PACÍFICO; MENDONÇA, 2010).

Em 1984, durante os debates do "Colóquio sobre Proteção Internacional dos Refugiados na América Central, México e Panamá: Problemas Jurídicos e Humanitários" (Cartagena/Colômbia), uma definição mais ampla do termo refugiado foi adotada e apresentada na Declaração de Cartagena de 1984. O documento define refugiado como sendo o indivíduo que tenha fugido do seu país por ameaça à vida, segurança ou liberdade resultantes da violência generalizada, da agressão estrangeira, dos conflitos internos, da violação maciça dos direitos humanos ou de outras circunstâncias que tenham perturbado gravemente a ordem pública (DOMINGUEZ; BAENINGER, 2005).

O Brasil acompanhou o processo de universalização do status de refúgio e, durante o processo de redemocratização, o país se comprometeu com dois instrumentos internacionais de proteção dos refugiados: a Convenção de 1951 e o Protocolo de 1967, mas adotou uma postura mais flexível, em consonância com a definição estabelecida pela Declaração de Cartagena de 1984 (JUBILUT, 2007).

Ainda em 1980, aconteceu a aprovação do Estatuto do Estrangeiro (Lei n 6.815/80), que regulamentava a situação do imigrante no Brasil, estabelecendo a ideologia de que estrangeiro representava uma ameaça à segurança nacional. Na mesma época, foi criado o Conselho Nacional de Imigração (CNIg) que, vinculado ao Ministério do Trabalho, da Justiça, das Relações Exteriores, da Agricultura e da Saúde, orientava e fiscalizava as situações de imigrantes no Brasil.

Na sequência, a Constituição Cidadã de 1988, baseada no princípio da dignidade humana, constitui, de forma sistemática, a proteção dos refugiados. A Carta Magna brasileira considera a dimensão supranacional, garantindo aos estrangeiros a proteção dos direitos fundamentais, abarcando, igualmente, os solicitantes de refúgio. Além disso, o artigo $5^{\circ}$ prevê a igualdade de direitos entre brasileiros e estrangeiros, garantindo a todos os residentes no Brasil as mesmas possibilidades de desenvolvimento humano, extinguindo qualquer diferenciação legal entre a nacionalidade dos indivíduos e superando a ideologia que circundava o Estatuto do Estrangeiro (SILVA, 2015).

A Lei Federal n 9.474/1997 providenciou a criação do CONARE - Comitê Nacional para os Refugiados, órgão multiministerial do qual participam o Governo e a Polícia Federal, a sociedade civil e a ONU com o objetivo de reconhecer, auxiliar e integrar os refugiados que chegam ao Brasil. 
Com todo esse aparato, "o Brasil passou a ter um sistema lógico, justo e atual de concessão de refúgio" (JUBILUT, 2007, p. 195), na medida em que uniformizou normativamente as disposições sobre o instituto do refúgio, servindo de paradigma como legislação avançada na temática. No entanto, somente em 2017 uma nova Lei de Migração (Lei n 13.445/2017) foi promulgada, em substituição ao Estatuto do Estrangeiro, estabelecendo novos direitos e os deveres do migrante e do visitante, mais condizentes com os desafios e contextos do Brasil contemporâneo. Dentre as inovações da Lei de Migração está a isenção de taxas por hipossuficiência econômica e vulnerabilidade.

O início do século XXI exigiu da Agência da ONU para Refugiados (ACNUR) mais ação com relação às grandes crises de refugiados na África, no Oriente Médio e na Ásia. Nesse ensejo, foi usada a experiência adquirida pelos anos de trabalho dentro da temática (desde 1951), na expansão do seu papel, no sentido de defender e advogar em prol dos muitos deslocados internos, devido a conflitos, ou mesmo de apátridas.

A crise dos refugiados na Europa, cujo ápice foi atingido em 2015, trouxe consigo muitos questionamentos sobre a situação desses indivíduos, não somente em seus países de origem, como, também, nos países de acolhimento. Consequentemente, uma série de levantamentos e estatísticas sobre essa questão começaram a ser desenvolvidos. Entre 2018 e 2019, cerca de 70,8 milhões de pessoas em todo o mundo foram forçadas a deixar seus lares. Desse montante, quase 25,9 milhões de refugiados têm menos de 18 anos de idade (UNHCR, 2019), ou seja, estão em idade escolar.

Essas leis e acordos internacionais reconhecem e tornam legítimos os direitos dos refugiados, atribuindo responsabilidades aos Estados de acolhida, que devem efetivar tais direitos por meio da implementação de políticas públicas. Essas políticas são ações que o Estado desenvolve com o intuito de transformar a sociedade, concretizar direitos humanos e garantir a efetivação dos direitos sociais e coletivos, assegurando os direitos constitucionais para aqueles que necessitam, seja nos âmbitos social, econômico, cultural e étnico (FRIEDRICH, 2014).

A maioria dos países professa o respeito pelo direito do migrante à educação, no entanto, esse acesso é, geralmente, limitado (BARTLET, 2015). A autossuficiência do indivíduo em situação de refúgio, em um primeiro momento, depende da implementação de normas, diretrizes e políticas públicas voltadas à Educação, já que estas aumentam as chances do indivíduo de trabalhar em sua área de formação e dar continuidade a seus estudos (JUBILUT, 2008), o que influenciará diretamente na sua conjuntura socioeconômica e, por consequência, na situação de vulnerabilidade.

A oportunidade de dar continuidade aos projetos de vida interrompidos é uma premissa fundamental do processo de adaptação do refugiado. Como já mencionado, dar seguimento à formação educacional imprime ideia de "normalidade", importante nesse momento, além de aumentar o potencial de empregabilidade dos indivíduos. Nesse sentido, a educação, de forma geral, notadamente o acesso ao Ensino Superior, não pode ser ignorada, uma vez que é parte importante do processo de integração dentro da noção de proteção integral de direitos, na qual devem ser assegurados os direitos intrínsecos à condição de "refugiado", bem como os demais direitos (JUBILUT, 2008).

\section{REFÚGIO E EDUCAÇÃO SUPERIOR}

Em uma perspectiva global de cidadania,2 que permite ao indivíduo pertencer simultaneamente a mais de uma comunidade política, a proteção integral às pessoas refugiadas

\footnotetext{
2 A abordagem globalizada de cidadania permite ao indivíduo pertencer simultaneamente a mais de uma comunidade política, criando estruturas integradas que contemplam direitos cívicos, sociais, culturais, políticos e de gênero, com o intuito de promover a construção de uma sociedade mais igual e diversificada. Cf. CASTLES, S.; DAVIDSON, A. Citizenship and Migration: Globalization and the Politics of Belonging. London: Macmillan Press. 2000.
} 
implica a garantia de todos os seus direitos. Nessa concepção global e plural, o processo de integração dos refugiados à sociedade brasileira passa pelo respeito às múltiplas identidades (LAPA et al., 2019).

Na dimensão social, a educação é base indispensável para a cidadania, motivo pelo qual as instituições de ensino devem estar aptas para acompanhar as novas dinâmicas sociais, sempre se renovando. A educação está entre as atividades mais elementares dentro de uma sociedade, atividades essas que, pela sua mutabilidade, se renovam pela evolução do conhecimento, resultante do ciclo de vida dos seres humanos (ARENDT, 2002).

Ademais, a educação é um agente importante de integração (AGER; STRANG, 2008) e a oportunidade de educação superior é um passo especialmente importante para a inclusão significativa dos indivíduos na sociedade. No entanto, em muitos casos, o acesso a ela ainda não é uma realidade para muitos grupos desfavorecidos ou vulneráveis.

Dentro do contexto de refúgio, além dos desafios cotidianos, os candidatos a ingresso no ensino superior comumente enfrentam dificuldades em adquirir proficiência no idioma local, $\mathrm{o}$ que restringe bastante sua capacidade de construção de rede social e pode, eventualmente, ser um obstáculo ao seu processo de aprendizagem (SHAKYA et al., 2012; FELIX, 2016). Além disso, os refugiados têm menos acesso às oportunidades de inserção no mercado de trabalho e à obtenção de renda, para as quais é necessária a complementação de estudos, cuja superação engloba o acesso ao ensino superior (LAPA et al., 2019).

Outro gargalo, que não está vinculado diretamente ao acesso ao ensino superior, mas o circunda, é a questão do reconhecimento e revalidação de diplomas. Justamente devido às circunstâncias excepcionais que caracterizam o refúgio, muitos requerentes não possuem documentos que comprovem suas qualificações educacionais anteriores (LAPA et al., 2019; STREITWIESER; TAYLOR, 2016) e, quando os têm, devem passar pela burocracia excessiva no processo de revalidação de diplomas estrangeiros no Brasil.

Tais considerações permitem que se afirme que a integração dos refugiados na sociedade não pode ser negligenciada, devendo ser um projeto coletivo. No entanto, observa-se que, frequentemente, confunde-se a ideia de integração na sociedade de acolhimento com a integração no ambiente acadêmico. São perspectivas diferentes, mas que se complementam, devido ao potencial de autodesenvolvimento oportunizado pelo acesso à educação formal.

Essa complementariedade responsabiliza, e, ao mesmo tempo, cria um leque de possibilidades de atuação para as IFES na promoção de ações de conscientização e valorização à diversidade, tanto dentro quanto fora dos muros da Academia, construindo um ambiente favorável e sensível às trocas culturais e ao multiculturalismo.

Também é comum vincular a ideia de acesso como sinônimo de inclusão social (GIDLEY et al., 2010), sobretudo no contexto de refúgio, no qual a vulnerabilidade é o desafio maior. Exatamente por essa questão, o acesso é apenas o primeiro passo em um sistema de políticas afirmativas.

Na definição do Grupo de Estudos Multidisciplinar da Ação Afirmativa da Universidade Estadual do Rio de Janeiro (GEMAA - UERJ, 2019), ações afirmativas são políticas que promovem oportunidades de acesso à educação, saúde, emprego, bens materiais, redes de proteção social e reconhecimento cultural dos grupos discriminados e marginalizados pela exclusão socioeconômica, no passado ou no presente.

Enquadrar as ações desenvolvidas dentro das IFES, com foco na população refugiada como afirmativas, pode apresentar certo anacronismo histórico questionável. Entretanto, dentro de uma perspectiva funcionalista, sua pertinência se justifica, haja vista que estas políticas visam combater discriminações étnicas, raciais, religiosas, de gênero ou de casta, com o objetivo de prevenir tanto a discriminação como contribuir para a reparação de seus efeitos, aumentando a participação de minorias no processo político.

Apesar de, conceitualmente, se contraporem à ideia de universalização das políticas públicas de educação, as políticas afirmativas se justificam no plano moral e social, tanto no 
sentido de fazer prevalecer o princípio da igualdade sobre o do mérito (FERES JÚNIOR, 2004), quanto na tentativa de fazer valer a concepção de algumas organizações ou indivíduos de que o ensino superior, oferecido em instituições públicas, é um bem público (MARGINSON, 2011).

No Brasil, o Ministério da Justiça tem monitorado a população de refugiados em território brasileiro desde 2010. Segundo dados da $4^{\mathrm{a}}$ Edição do relatório Refúgio em Números, até dezembro de 2018 há um acumulado de 11.231 mil pessoas refugiadas, já reconhecidas pelo CONARE, e 161.057 mil solicitações de reconhecimento da condição de refugiado em trâmite. Dessas 11.231 pessoas reconhecidas como refugiadas, atualmente $6.554^{3}$ mantêm essa condição no país. Com relação à nacionalidade e ao gênero, o maior número de refugiados recebidos é proveniente da síria (36\%) e há uma predominância do sexo masculino (72\%) (BRASIL, 2019).

No que tange ao âmbito educacional, a pesquisa Perfil Socioeconômico dos Refugiados no Brasil revela uma alta taxa de escolaridade dos refugiados residentes no país: $34,4 \%$ dos entrevistados possuem o ensino superior e 49,6\% concluíram o ensino médio. Observa-se que esse índice é bastante elevado, se for considerado em relação ao percentual de brasileiros, na faixa etária de 25 anos ou mais, quando apenas 16,5\% possuem nível superior completo e $27 \%$ concluíram o Ensino Médio (IBGE, 2018). Ainda conforme a pesquisa, mais da metade dos entrevistados demonstraram desejo de estudar no país. Importante observar que 88,26\% está na faixa-etária economicamente ativa, com idades entre 18 e 49 anos (ACNUR, 2019).

Apesar desses índices de escolarização dos refugiados, o Governo Federal reconhece a vulnerabilidade social em que eles se encontram. Em função disso, a revalidação de diploma e o acesso de refugiados às instituições públicas de ensino são reconhecidos pelo Art. 44 do Estatuto dos Refugiados (Lei ${ }^{\circ}$ 9.474/97) e devem ser facilitados, o que demanda ações do Governo para a efetivação deste direito, em todas as esferas.

Nesse cenário, a educação superior se destaca como um dos principais pilares para o recomeço de vida da população migrante vulnerável, pois é medida de garantia do pleno desenvolvimento do ser humano e de sua dignidade. O cumprimento do direito ao acesso ao Ensino Superior passa por inúmeras outras etapas, que vão desde a implementação de mecanismos de garantia à operacionalização do acesso e, principalmente, permanência.

Um estudo, cujo objetivo foi levantar as diferentes intervenções realizadas no contexto dos sistemas de Educação Superior australiano e europeu, destinadas à população refugiada, e que foram implementadas por governos anfitriões, instituições de ensino e organizações nãogovernamentais, entre outros, foi desenvolvido por Jennifer M. Gidley et al. Nesse estudo, ainda, os autores buscam analisar o potencial de promover a integração de tais intervenções no contexto acadêmico, para cuja análise desenvolveu um marco analítico da integração no Ensino Superior com base em três níveis, o que chamaremos de 3E's: equidade de acesso; engajamento participativo e empoderamento (GIDLEY et al., 2010).

\section{OS 3 E'S DE GIDLEY ET AL.}

Dentro do contexto do marco de análise dos níveis de integração do ensino superior sob o qual estaria suscetível a população refugiada, a equidade de acesso é a forma mais básica de inclusão social no contexto do Ensino Superior. Ela trata não somente da entrada na Universidade em si, mas também contempla medidas institucionais, como bolsas de estudo, outras formas de auxílio financeiro, infraestrutura adequada aos estudos, assistência pedagógica e oportunidades de aprendizagem. No contexto brasileiro, podem ser mencionadas aqui as políticas afirmativas e de permanência, como vestibular específico, editais de reingresso, auxílios moradia e alimentação, bolsas de tutoria e docência, assistência pedagógica e psicológica, entre outras.

\footnotetext{
3 "É possível dizer que algumas pessoas se naturalizaram brasileiros/as, retornaram ao país de origem, tiveram a cessação da condição de refugiado, faleceram, optaram pela residência, entre outras situações comuns da vida". Fonte: Polícia Federal (em 24 maio 2019).
} 
O segundo nível, o engajamento participativo, diz respeito às questões que envolvem a dignidade humana. Sob esta perspectiva, a inclusão social está diretamente relacionada aos direitos humanos, igualdade de oportunidades e justiça para todos, não necessariamente com vinculação econômica (GIDLEY et al., 2010). Tais ações têm como alvo permitir que todos os seres humanos participem plenamente da sociedade e que haja respeito pela sua dignidade humana.

Em termos práticos, dentro do espectro de ações desenvolvidas dentro das IFES, podemos mencionar cursos de idioma, empreendedorismo social, atividades esportivas e artísticas, ações de conscientização e foco na valorização da diversidade, bem como prevenção e combate ao preconceito, instalação de espaços de diálogo e de partilha de experiências, eventos de promoção e, ainda, o intercâmbio cultural e incentivo à construção de redes de apoio.

Torna-se importante ressaltar que as ações, acima elencadas, contribuem para oportunizar e sedimentar as relações sociais desses indivíduos, relações essas que desempenham um papel fundamental na garantia de oportunidades educacionais para crianças e jovens migrantes, servindo como um recurso que possibilita que os indivíduos participem de novas redes "de conhecimento mútuo e reconhecimento" (BOURDIEU; WACQUANT, 1992, p. 119).

O terceiro e último nível é o ideal a ser buscado: o empoderamento. Este, entendido, sob a perspectiva "freiriana", como a capacidade de realizar, por si mesmo, as transformações e ações que propiciem e culminem na sua evolução e fortalecimento (VALOURA, 2011), podendo ser expandida para indivíduos, grupos de pessoas e instituições. Esse é o nível de integração mais compreensivo, já que reconhece a complexidade e unicidade dos indivíduos, ao considerar sua capacidade de participar da sociedade como agente de mudança e reforço do processo de integração e, porque se evidencia por meio da participação social, acaba por extrapolar o universo acadêmico. Acontecem, então, as intervenções de promoção da cidadania e participação cidadã, aliadas à construção de redes e associações, bem como a organização de movimentos de defesa e garantia de direitos e representatividade acadêmica. Abrem-se, também, espaços de escuta às reinvindicações e debates que objetivam a promoção da conscientização civil sobre os direitos sociais e civis.

Além dos ganhos individuais que a integração ao ensino superior pode propiciar à população refugiada, colaborando consideravelmente na atenuação de seu estado de vulnerabilidade e favorecimento do processo de empoderamento, esse tipo de prática também traz importantes ganhos institucionais, sendo esse um tópico rico e pertinente para um estudo futuro.

As universidades federais brasileiras, como autarquias, dotadas de autonomia e independência, através de seus órgãos colegiados, definem, em parte, seus sistemas de ingresso. Com base nessa autonomia universitária, garantida pelo artigo 207 da Constituição de 1988, algumas IFES brasileiras têm implementado intervenções em favor do acesso e integração da população refugiada no ensino superior. Dentre elas, destaca-se a UFPR, da qual trataremos adiante.

Para melhor entender a relação entre ensino superior e integração, seguindo o esquema dos níveis de integração de Gidley et al., serão avaliadas algumas das ações implementadas no contexto do PMUB.

\section{PROGRAMA POLÍTICA MIGRATÓRIA E UNIVERSIDADE BRASILEIRA}

O Programa Política Migratória e Universidade Brasileira (PMUB) remonta ao ano de 2013, com a assinatura do termo de parceria entre a Universidade Federal do Paraná e o Alto Comissariado das Nações Unidas para Refugiados (ACNUR) - dentro da Cátedra Sérgio Vieira de Mello (CSVM). Em 2015, a parceria recebe reforços por meio da assinatura de um convênio com o Ministério Público do Trabalho, no Paraná (MPT/PR) (GEDIEL; GODOY, 2016). 
O PMUB tem duas frentes de atuação. A primeira diz respeito às atividades que contemplam a comunidade refugiada, como cursos de informática, assistência jurídica e, de forma mais compreensiva, a discussão e formulação de instrumentos legislativos, bem como o acompanhamento das políticas públicas existentes, pertinentes ao refúgio, migração e apatridia. Fazem parte dessa pauta de discussões, também, o acolhimento e a busca de soluções duráveis e sustentáveis para refugiados e migrantes na universidade e na sociedade local, assim como o combate ao trabalho escravo e precário de refugiados e migrantes, em parceria com o MPT/PR através de termo de cooperação firmado em 2015.

Na segunda, a atuação do PMUB se concentra na questão institucional, concentrando esforços na elaboração de instrumentos institucionais e de auxílio a refugiados e migrantes nos processos de revalidação de diplomas estrangeiros; na seleção e no acolhimento de refugiados e migrantes que ingressam na UFPR; no incentivo a atividades de pesquisa e ensino que tenham como finalidade discutir e aprofundar a temática do refúgio, da migração e da apatridia.

O programa se vincula aos aspectos jurídicos do direito internacional e humanitário, sendo fundamentado no ideal de hospitalidade incondicional, com o objetivo de viabilizar e proporcionar novos momentos de encontro com o outro, principalmente quando o outro se encontra em desigualdade social e fragilidade em seus direitos. Assim, busca-se a formação de um laço mais humano, interativo e dinâmico, fomentando a hospitalidade e o acolhimento .

Historicamente, a questão do acesso do refugiado à UFPR se originou com a solicitação de reingresso, no curso de Arquitetura e Urbanismo, de uma refugiada síria, cuja demanda individual desencadeou um conjunto de ações institucionais que culminou no que se estrutura hoje como o PMUB.

Antes de 2013, algumas atividades, que posteriormente foram aglutinadas ao PMUB, já eram desenvolvidas, de maneira isolada, por diferentes departamentos da UFPR, não necessariamente de maneira institucionalizada. Por exemplo, desde 2013 já eram ofertadas aulas de português para refugiados e migrantes, pelo curso de Letras, em parceria com o Centro de Línguas Estrangeiras da Universidade Federal do Paraná (CELIN/PR) .

Esse leque de intervenções permitiu a construção de uma capacidade institucional que resultou em uma abordagem integrada da questão do refúgio, composta pelos projetos: Português Brasileiro para Migração Humanitária (PBMIH), do curso de Letras; Refúgio, Migração e Hospitalidade, do curso de Direito; Capacitação em Informática para Imigrantes, do curso de Informática; e Migração e processos de subjetivação, do curso de Psicologia. Tais projetos desenvolvem suas atividades de forma autônoma e independente, de acordo com seu meio de atuação. À medida que novas demandas são identificadas, outras ações se agregam às que estão em desenvolvimento, em um processo de evolução contínua.

Com o princípio orientador de acompanhar o refugiado de maneira global e integrada, a Universidade oferece serviços que atendem às necessidades, individuais ou do grupo, dentro de uma perspectiva de acolhimento e hospitalidade. Entre 2014 e 2018, mais de $1.500^{4}$ migrantes e refugiados foram assistidos pelo PMUB entre atendimentos jurídicos, aulas de português e informática, e outros 5.000 participaram de atendimentos psicológicos (UFPR, 2019a).

Seguindo a classificação de Gidley et al., as intervenções que dizem respeito à equidade de acesso no contexto do PMUB são as Resoluções 13/14 e 63/18, do Conselho de Ensino, Pesquisa e Extensão (CEPE) da UFPR que, respectivamente, estabelecem as normas para acesso de migrantes regularmente admitidos no Brasil, que tenham iniciado cursos superiores em instituições de ensino no estrangeiro, aos cursos de graduação da UFPR (reingresso) e aprova o lançamento de criação de um vestibular específico destinado ao preenchimento de vagas suplementares nos cursos da Universidade Federal do Paraná - o último acompanhado pela criação do Cursinho Preparatório para tal prova.

\footnotetext{
${ }^{4}$ Dados dos arquivos PMUB.
} 
Já quanto ao engajamento participativo, podem ser citadas apresentações culturais como "Literatura de Refúgio" onde, por meio de poesias e expressões culturais, os refugiados compartilham as suas experiências de vida e suas histórias de migração forçadas. São organizadas, também, oficinas de vídeos, denominadas "Oficina: feitos de Coragem" e são realizadas campanhas, como "Recomeços são Possíveis", de ação interna da Universidade, visando combater o preconceito e favorecer o acolhimento dos refugiados no contexto acadêmico. Também são realizadas celebrações pelo Dia do Refugiado e a Semana do Migrante, com o tema "Encontros Inesperados", para sensibilização da causa do refúgio. Todas essas ações visam à construção de um espaço de expressão e troca de saberes entre o recém-chegado e a sociedade de acolhimento.

Os serviços diretos prestados pelo PMUB tais como: i) assistência jurídica ("Refúgio, migrações e hospitalidade"); ii) investigação científica ("Migrantes no Paraná: Preconceito, Integração e Capital de Mobilidade"), monitoramento dos fluxos em parceria com Observatório de Migrações do Paraná e Pesquisas sobre Migrações Internacionais e Multiculturalismo; iii) rede de Atendimento Psicológico aos Migrantes ("Migração e Processos de Subjetivação: Psicanálise e Política"); iv) aulas de Português Brasileiro para Migração Humanitária (PBMIH); v) cursos de capacitação em Informática; vi) plantões de acolhimento psicológico/acadêmico (PermaneSendo e Programa de Tutoria) e as Oficinas de História do Brasil, que buscam promover e instrumentalizar a população refugiada para o enfrentamento e entendimento da nova realidade, propiciando-lhe uma participação plena.

Em dezembro de 2019, foi aprovado o chamado Programa de Formação Suplementar: Ciclo de Acolhimento Acadêmico para Estudantes Refugiados (PFS-Refugiados), que promove tanto a equidade de acesso, no sentido de prover ações de permanência dos refugiados na Academia, quanto facilita a adaptação e a inserção destes à vida universitária e social do País, de modo a ampliar as chances de sucesso no processo de inclusão no contexto sociocultural brasileiro através da formação universitária (UFPR, 2019b). De maneira simplificada, esse "ano zero" constituiria em uma formação continuada de cerca de 500 horas, composta por aulas de Português como língua estrangeira (PLE), por módulos de história e temas relacionados à atualidade da sociedade brasileira, direito brasileiro, entre outros.

Finalmente, a oferta de aulas de Creole, ministradas pelos refugiados haitianos, consiste em parte de uma intervenção do nível de empoderamento. Apesar de ainda muito incipientes, essas ações se constituem no embrião de uma participação social, na qual o indivíduo é protagonista e representante do processo de intercâmbio, que acontece com maior bilateralidade do que as intervenções de cunho cultural. Isso permite um acomodamento, um espaço de expressão de articulação entre a cultura do país de origem e o de refúgio.

Como resultado, verifica-se que há uma predominância das atividades de equidade de acesso e engajamento participativo em detrimento das ações de empoderamento. Isso pode se justificar pelo largo espectro de atuação do PMUB, que extrapola o ambiente acadêmico propriamente dito, resultando em atuação política e social.

A atualidade e urgência do desafio do refúgio, no contexto da UFPR, também evidenciam essa predominância. Como já mencionado, num primeiro momento, a prioridade é instrumentalizar o refugiado com ferramentas de enfrentamento da nova realidade, ou seja, permitir a construção de um repertório de capacidades que lhe permitam empreender o entendimento jurídico, cultural e social da sociedade de acolhimento.

Finalmente, o último nível de integração, o empoderamento, além de ser o mais complexo, também requer tempo, o que pode ter se traduzido em uma quantidade bem menor de ações. Talvez, as intervenções com esse foco virão no futuro, como fruto das demais intervenções.

A questão do refugiado é uma demanda latente e em crescimento. Assim, idealmente, é necessário pensar em âmbito nacional, em política pública executada e legitimada pelo Governo Federal, que possa atender, de maneira mais significativa, à demanda de entrada dos refugiados no ensino superior de maneira integrada, garantindo direitos e propiciando o exercício da cidadania. 


\section{CONSIDERAÇÕES FINAIS}

Em razão da nova dinâmica dos fluxos migratórios, a proteção e acolhida requer uma ação integrada dos diversos atores envolvidos. Compete ao Governo Federal articular mecanismos de integração local dessa população vulnerável, a fim de evitar disparidades socioeconômicas e injustiças sociais, que alterem a dinâmica das cidades. É necessária a efetivação de uma ação conjunta que vise, não somente à inclusão do refugiado, mas também à aceitação deste pela sociedade de acolhimento, aspectos que não podem ser negligenciados.

Discutir a questão dos refugiados passa, primordialmente, pela elaboração de políticas públicas afirmativas inclusivas no ensino superior, que entendam essa integração como um processo contínuo a fim de garantir, não apenas o acesso dessa população ao Ensino Superior, como, também, sua permanência no sistema educacional. Em última instância, o processo de empoderamento exige mecanismos que favoreçam sua implementação.

A expansão do acesso ao ensino superior é um fator essencial na promoção da integração continuada, que pressupõe uma relação harmoniosa entre a cultura do país de origem e do país de acolhimento (KNIGHT, 2003) e é fundamental para evitar a segregação e marginalização.

A autonomia universitária muito colaborou para que as Instituições de Ensino Superior Federais fossem capazes de desenvolver políticas de acesso, e pode colaborar ainda mais no sentido de definir currículos mais multiculturais, como uma oportunidade de expandir a formação profissional dentro da perspectiva de uma formação integradora e humana (LIBÂNEO, 2012). Isso permitiria ao futuro profissional desenvolver habilidades que vão além do conhecimento técnico, tornando-o mais instrumentalizado para enfrentar os novos contextos de trabalho fortemente influenciados pela pluralidade. $\mathrm{O}$ incentivo à formação acadêmica dos refugiados também apresenta potencial de agregar capital intelectual às comunidades nas quais estes se estabelecem, contribuindo para o desenvolvimento regional, mas ainda há muito a ser feito.

As instituições públicas de ensino superior apresentam-se como agentes de integração de alta relevância, pois o ensino e a qualificação possibilitam que os refugiados alcancem autonomia pessoal, econômica e profissional. Essas instituições cumprem um papel de influenciar e transformar a realidade social, fortemente vinculado ao tripé da extensão (Ensino, Pesquisa e Extensão).

A análise das ações desenvolvidas no contexto do PMUB mostrou o potencial e a complexidade do processo de promoção da integração. O ambiente universitário, principalmente das IFES, tem uma vocação e obrigação com a pluralidade, uma vez que a interação entre diferentes atores tende a promover trocas e aprendizagens únicas. $\mathrm{O}$ desenvolvimento de atividades que promovam a interculturalidade e o intercâmbio de experiência incrementam o processo de aprendizagem e construção do conhecimento, resultando na formação de profissionais mais integrados e preparados para um mercado de trabalho globalizado. Para as instituições, tais ações não apenas colaboram na construção de uma reputação e visibilidade nacionais e internacionais (internacionalização), como desenvolvem competências institucionais e expertise antes inexistentes.

Entretanto, essas ações ainda ocorrem em um contexto micro, sendo desenvolvido, em cada Universidade, de maneira e envergadura diferentes. Em um efeito de mimetismo institucional, são necessárias políticas públicas de abrangência nacional, já que estas são delineadas e delineiam os entendimentos sociais. São necessárias políticas inclusivas que envolvam todos os agentes da sociedade - União, Estados, Municípios e sociedade civil, pois são essas políticas que influenciam nos fenômenos da migração e como os próprios imigrantes são percebidos pela sociedade.

A análise das ações na UFPR demonstrou que há uma evolução natural do tipo de intervenção realizada que acompanha a evolução do processo de integração. Porém, o caráter recente da temática ainda não permite uma análise mais profunda do que foi feito até o 
momento. O que se percebe é um aumento nas ações de engajamento participativo, o que demonstra um interesse da população refugiada em se expressar e interagir com sua nova comunidade - o que dá pistas de que o caminho que está sendo trilhado parece funcionar.

As ações afirmativas funcionam no sentido de que há uma aderência e uma significância para a comunidade para a qual esta foi elaborada, entretanto a relação demanda e oferta tem potencial para se tornar um gargalo à medida que os números aumentam. A falta de dados acurados sobre a localização, quantidade e perfil da população refugiada tende a esconder a realidade da situação. Assim, a continuidade dessas ações deve ser acompanhada a fim de que sejam avaliadas as medidas adotadas até o momento, buscando saber se são realmente suficientes e quais barreiras ainda existem, apontando para melhorias e possibilidade de expansão dessas ações para outras instituições do estado e do país, por meio de uma ação de abrangência Federal.

O valor desta pesquisa ultrapassa o ambiente acadêmico. Ao tratar de um assunto emergente e de grande importância social, ela busca sensibilizar a sociedade e os agentes de decisão em prol de um planejamento articulado e integrado das medidas de integração, planejamento esse que considere os impactos e desdobramentos, a médio e longo prazo, de ações que são realizadas em um contexto altamente frágil e volátil. Espera-se que a pesquisa auxilie as Instituições de Ensino em reflexões a respeito das intervenções desenvolvidas e práticas cotidianas, com o objetivo de promover a integração dos refugiados dentro do contexto do ensino superior brasileiro. Espera-se, também, que a sociedade possa ser sensibilizada a respeito da necessidade de medidas mais abrangentes, que excedam o campo da educação.

Parafraseando a metáfora de Mehta, o que se busca não é incluir a todos, mas sim não excluir ninguém. Ou seja, não é necessário que você seja convidado para todas as festas na praia, a ideia é que, em algum lugar na praia, haja uma festa na qual possa ir (MEHTA, 2015).

\section{REFERÊNCIAS}

ACNUR. Brasil tem quase 9 mil refugiados de 79 nacionalidades. 2016. Disponível em: https://www.acnur.org/portugues/2016/05/10/ brasil-tem-quase-9-mil-refugiados-de-79nacionalidades/. Acesso em: 01 nov. 2019.

ACNUR. Perfil Socioeconômico dos Refugiados no Brasil. 2019. Disponível em: https://www.acnur.org/portugues/wp-content/uploads/2019/05/Resumo-ExecutivoVersa\%CC\%83o-Online.pdf. Acesso em:14 jun. 2019.

AGER, A.; STRANG, A. Understanding integration: A conceptual framework. Journal of Refugee Studies, v. 21, n. 2, p. 166-191, 2008.

ARENDT, H. Entre o Passado e o Futuro. Traduzido por Mauro W. Barbosa de Almeida. São Paulo: Perspectiva, 2002.

ASSIS, G. de O. Nova Lei de Migração no Brasil: Avanços e Desafios. In: BAENINGER, Rosana et al. Migrações Sul-Sul. 2. ed. Núcleo de Estudos de População "Elza Berquó" - Nepo/Unicamp. Campinas, p. 609-622, 2018.

BARTLETT, L.; RODRÍGUEZ, D.; OLIVEIRA, G. Migração e educação: perspectivas socioculturais. Educação e Pesquisa, v. 41, n. especial, p. 1153-1171, 2015.

BRASIL. Lei Federal n. 13.445, de 24 de maio de 2017. Brasília, DF: Senado Federal, 2017. Disponível em: http://www.planalto.gov.br/ccivil_03/_ato2015-2018/2017/lei/113445.htm. Acesso em: 29 maio de 2019.

BRASIL. Constituição da República Federativa do Brasil de 1988. Brasília, DF: Senado Federal, 1988. Disponível em: https://www.planalto.gov.br/ccivil_03/Constituicao/Constituicao.htm. Acesso em: 29 maio 2019. 
BRASIL. Ministério da Justiça. Refúgio em números. 4. ed. 2019. Disponível em: https://www.justica.gov.br/seus-direitos/refugio/refugio-em-numeros/. Acesso em:01 nov. 2019.

BRASIL. Lei Federal n. 9.474, de 22 de julho de 1997. Brasília, DF: Senado Federal, 1997. Disponível em: http:/ / www.planalto.gov.br/ccivil_03/Leis/L9474.htm. Acesso em:29 maio 2019.

BUSKO, D. Políticas públicas educacionais para imigrantes e refugiados no Rio Grande do Sul. Jornal Políticas Educacionais, v. 11, n. 22, p. 1-20, 2017.

CALAZANS, A. M.; PACÍFICO, P.; MENDONÇA, R. de L. A proteção sociojurídica dos refugiados no Brasil. Textos e Contextos, v. 9, n. 1, p.170-181, 2010.

CASTLES, S.; DAVIDSON, A. Citizenship and Migration: Globalization and the Politics of Belonging. London: Macmillan Press. 2000.

DE CARVALHO, E. O Ensino Superior Brasileiro e o seu papel no acolhimento de refugiados: o caso pioneiro da UFPR. In: Simpósio Brasileiro de Desenvolvimento Territorial Sustentável (SBDTS), 3, 2019. Anais [...]. Matinhos, 2019.

DOMINGUEZ, J. A.; BAENINGER, R. Programa de Reassentamento de Refugiados no Brasil. 2005. Disponível em: http://www.abep.org.br/publicacoes/index.php/anais/article/view/1583. Acesso em:01 nov. 2019.

DRYDEN-PETERSON, S. Refugee Education: the crossroads of globalization. Educational Researcher, v.45, n.9, p.473-482, 2016. Disponível em: https://doi.org/10.3102/0013189X16683398. Acesso em: 01 nov. 2019.

FELIX, V. R. The Experiences of Refugee Students in United States Postsecondary Education. PhD, Bowling Green State University. Retrieved. 2016. Disponível em: https://etd.ohiolink. edu/!etd.send_file?accession=bgsu1460127419\&amp;disposition=inline. Acesso em:01 nov. 2019.

FERES JÚNIOR, J. Ação Afirmativa no Brasil: fundamentos e críticas. Economia, v. 6, n. 2, p. 291-312, 2004.

FRIEDRICH, T. S.; FRIEDRICH, N. M. Políticas Públicas, Direitos Humanos e Cidadania em Relação à Água: o caso do Programa Cultivando Água Boa da Itaipu Binacional. In: SILVA, E. F.; GEDIEL, J. A. P.; TRAUCZYNSKI, S. C. Direitos humanos e políticas públicas. Curitiba: Universidade Positivo, 2014.

FRIEDRICH, T.; RUANO, B. P.; SCHMITT, E. C.; GRAHLX, J. A.; GEDIEL, J. A. P.; KÜNZLE, L. A.; OLIVEIRA, M. DE; GARRAFONI, R. S.; REZENDE, T. Z. Política Migratória e Universidade Brasileira: a experiência do atendimento a haitianos e outros migrantes na UFPR. PÉRIPLOS. Revista de Pesquisa sobre Migrações, v. 1, n. 1, 2017.

GEDIEL, J. A. P.; GODOY, G. G. de. Refúgio e Hospitalidade. Curitiba: Kairós Edições, 2016.

GEMAA. O que são ações afirmativas? Disponível em: http:/ / gemaa.iesp.uerj.br/o-que-sao-acoesafirmativas/. Acesso em:01 nov. 2019.

GIDLEY, J. M. et al. From access to success: An integrated approach to quality higher education informed by social inclusion theory and practice. Higher Education Policy, v. 23, n. 1, p. 123-147, 2010.

IBGE. Pesquisa Nacional por Amostra de Domicílios Contínua (PNAD Contínua). Rio de Janeiro, 2018. Disponível em: https://educa.ibge.gov.br/jovens/conheca-o-brasil/populacao/18317educacao.html. Acesso em: 18 dez. 2019.

JUBILUT, L. L.; MADUREIRA, A. de L. Os desafios de proteção aos refugiados e migrantes forçados no marco CARTAGENA + 30. REMHU-Rev. Interdiscip. Mobil. Hum, n. 43, p. 11-33, 2014.

JUBILUT, L. L. O direito internacional dos refugiados e sua aplicação no ordenamento jurídico brasileiro. São Paulo: Método, 2007.

JUBILUT, L. L.; APOLINÁRIO, S. M. DE O. S. A população refugiada no Brasil: em busca da proteção integral. Universitas - Relações Internacionais, v. 6, n. 2, p. 9-38, 2008. 
KNIGHT, J. Internationalization of Higher Education: Practices and Priorities 2003 IAU Survey Report. Paris: International Association of Universities, 2003. Disponível em: https://iauaiu.net/IMG/pdf/internationalisation_2003_0.pdf. Acesso em:26 ago. 2019.

KUGIEL, P. The Refugee Crisis in Europe: True Causes, False Solutions. The Polish Quarterly of International Affairs, Warsaw, n. 4, p. 41 - 59, 2016.

LAPA, R. et al. Documentos para o acesso de pessoas refugiadas ao Ensino Superior no Brasil Relatório de Pesquisa. Santos: Cátedra Sérgio Vieira de Mello da Universidade Católica de Santos, 2019.

LIBÂNEO, J. C. O dualismo perverso da escola pública brasileira: escola do conhecimento para os ricos, escola do acolhimento social para os pobres. Educação e Pesquisa, v. 38, n. 1, p. 13-28, 2012.

MARGINSON, S. Higher Education and Public Good. Higher Education Quarterly 65(4): 411-433. 2011.

MEHTA, S. Beyond the Maximum: Cities May be Booming, but Who's Invited to the Party? The Guardian, 30 nov. 2015.

ONU. Declaração Universal dos Direitos Humanos, 1948. Disponível em: http:/ / www.ohchr.org/ EN/UDHR/Pages/Language.aspx?LangID=por. Acesso em:02jun. 2019.

RAMOS, A. de C. 60 anos de ACNUR: perspectivas de futuro. São Paulo: CL-A Cultural, 2011.

SHAKYA, Y. B. et al. Aspirations for higher education among newcomer refugee youth in Toronto: Expectations, challenges, and strategies. Refuge, 27(2), 65-78, 2012.

SILVA, J. A. da. Curso de Direito Constitucional Positivo. 38. Ed. São Paulo: Malheiros, 2015.

SILVA, K. DE S. et al. Santa Catarina no roteiro das diásporas: os novos imigrantes africanos em Florianópolis. Revista Katálysis, v. 21, n. 2, p. 281-292, 2018.

SMAILI, S. S. Migrantes, pós-colonialismo e fundamentalismo: enlaces entre Oriente e Ocidente e a questão do Islã. Psicologia USP, Scielo, v. 26, p. 145 - 151, 08 2015. ISSN 0103-6564.

STREITWIESER, B.; TAYLOR, M. Credentialing Procedures for Migrants Seeking Entrance to German Higher Education. IEM Spotlight Newsletter, v. 13, Issue 2, 1-6. 2016.

STREITWIESER, B. et al. Access to Higher Education for refugees: A Review of Interventions in North America and Europe. 2018.

STREITWIESER, B.; UNANGST, L. Access for Refugees into Higher Education: Paving Pathways to Integration. International Higher Education, n. 95, p. 18-20, 2018.

UFPR. Homenageados do Aniversário de 107 anos da UFPR: Programa de Política Migratória é destaque em extensão. 2019a. Disponível em: https://www.ufpr.br/portalufpr/noticias/ homenageados-do-aniversario-de-107-anos-da-ufpr-programa-de-politica-migratoria-e-destaqueem-extensao/. Acesso em:11 dez. 2019.

UFPR. Cepe aprova iniciativa para aprimorar o acolhimento e a adaptação de migrantes e refugiados. 2019b. Disponível em: https://www.ufpr.br/portalufpr/noticias/cepe-aprovainiciativa-com-objetivo-de-aprimorar-o-acolhimento-e-a-adaptacao-de-estudantes-migrantes-erefugiados/. Acesso em:19 dez. 2019

UFPR. Resolução n. 13/14-CEPE. Conselho de Ensino, Pesquisa e Extensão da Universidade Federal do Paraná. Disponível em: http://www.soc.ufpr/portal/wp-content/uploads/2016/07/ resolucao_cepe_09072014-902.pdf. Acesso em: 28 maio 2019.

UFPR. Resolução n. 63/18-CEPE. Conselho de Ensino, Pesquisa e Extensão da Universidade Federal do Paraná. Disponível em: http:/ / www.soc.ufpr.br/ portal/ wp-content/uploads/2018/11/cepe-6318-vagas-suplementares-migrantes.pdf. Acesso em: 28 maio 2019. 
UNHCR. Forced displacement worldwide at its highest in decades. 2017. Disponível em: https://www.unhcr.org/news/stories/2017/6/5941561f4/ forced-displacement-worldwide-itshighest-decades.html. Acesso em:01 nov. 2019.

UNHCR. Figures at a Glance. 2019. Disponível em: https://www.unhcr.org/figures-at-aglance.html. Acesso em: 01 nov. 2019.

VALOURA, L. DE C. Paulo Freire: o educador brasileiro autor do termo Empoderamento, em seu sentido transformador. In: M. Schiavo (Ed.). [Social residence: $\mathrm{Na}$ innovative program by Comunicarte - social responsibility agency]. Residência social: Um programa inovador da Comunicarte-agência de responsabilidade social (pp.141-155). Rio de Janeiro: Comunicarte, 2011.

\section{INFORMAÇÕES DAS AUTORAS}

\section{Elisa de Carvalho}

Doutoranda do Programa de Pós-Graduação em Planejamento e Governança Pública (PPGPGP) da Universidade Tecnológica Federal do Paraná.

E-mail:lisacris@gmail.com

Orcid: https:/ / orcid.org/0000-0003-0348-6125

Lattes: http:/ / lattes.cnpq.br/1124558185002310

\section{Elisa Perelles}

Mestranda do Programa de Pós-Graduação em Planejamento e Governança Pública (PPGPGP) da Universidade Tecnológica Federal do Paraná.

E-mail: elisaperelles@gmail.com

Orcid: https:/ / orcid.org/0000-0002-5022-7938

Lattes: http:/ / lattes.cnpq.br/5776239874517548

\section{Maria Lucia Figueiredo Gomes de Meza}

Doutora em Desenvolvimento Econômico pela Universidade Federal do Paraná (UFPR), Diretora de Relações Empresariais e Comunitárias da Universidade Tecnológica Federal do Paraná (UTFPR), Coordenadora do Curso de Especialização em Gestão Pública Municipal e Professora da UTFPR, atuando no Mestrado e Doutorado Profissional em Planejamento e Governança Pública e no Mestrado em Administração.

E-mail:malumeza2@gmail.com

Orcid:https:/ / orcid.org/0000-0002-1875-5140

Lattes: http:/ / lattes.cnpq.br/3634990002513047

Recebido em: 08/10/2020

Aceito em: 06/04/2021 